\title{
RESEARCH ETHICS COMMITTEES AND ETHICAL CODES - IMPLICATIONS FOR THE HEALTHCARE CHAPLAIN
}

\section{Iain Atherton}

Abstract: In this paper Iain raises important issues about how the process of applying for ethical
permission should be viewed as more than a bureaucratic exercise. Hospital chaplains can take
advantage of their personal experience and expertise to engage fully with the process and to help
develop thinking around ethical issues. Whilst every author in this edition has probably had some
kind of irritation around applying for and receiving NHS ethical approval for research, the reality
is that doing research ethically and ethical research remains a challenge, one which healthcare
chaplains are well placed to meet. The research ethics committee should be seen as a resource
with which to engage and a help in refining the proposal.

Key Words: ethics, research, chaplaincy,

My aim in this paper is to encourage hospital chaplains engaging in research to consider the ethical dimensions of their work beyond the criteria of ethics codes or committees. Hospital chaplains are well equipped to engage in critical thinking on ethics both for their own research and to contribute to wider debate. Reflection on ethical dimensions can not only help develop more robust proposals but also enrich the experience of carrying out research.

Hospital chaplains engaging in research will very likely feel daunted at the prospect of addressing ethical issues and negotiating the need for the approval of ethics committees (indeed not only hospital chaplains). Research involves many potential problems that, if they arose, would cause harm and distress to participants. Any research involving NHS staff or patients is required to be scrutinised and accepted by the NHS's own ethics committee, a process that involves addressing challenging questions. The chaplain will therefore take considerable time in thinking through how to proceed. Codes produced by many different learned bodies might be consulted (for example the British Sociological Association, 2002; Royal College of Nursing, 2009; and the Social Research Association, 2003). The chaplain may wonder whether carrying out research is worth their while when complex and time consuming forms. Any negative response from an ethics committee will understandably make the chaplain even more reticent to proceed, maybe even to give up. The whole process can feel disempowering and bureaucratic.

My intention with this paper, however, is to encourage hospital chaplains who are engaging in research to recognise their own role in developing ethically robust proposals. I contend that the ethical process can add to the whole experience, being both personally enriching and improving the quality of a research proposal. Research ethics encompass a huge range of issues on which I can only briefly touch. However, this paper is not intended to be comprehensive; rather, it is intended to stimulate thinking about our own responsibilities. Research is not ethical simply because the proposal has an ethics committee's approval or follows guidelines set out in ethical codes. Ethical issues are difficult to codify and, when problems arise, decisions are rarely straightforward. However, chaplains have considerable experience in dealing with complex ethical dilemmas in their work. They are thus well placed to not only take responsibility for their research but also to contribute to debates around research ethics. Their religious and spiritual perspective can provide an angle on dilemmas that might be missed were the medical model to be the only viewpoint to be used. Far from putting off chaplains engaging in research my aim is therefore to encourage active participation in the ethics of their research. 
Research now almost invariably requires the assent of an ethics committee, and with good reason. Review by an ethics committee provides independent scrutiny of a proposal. Far from being intimidated by such a prospect chaplains can view the process as an opportunity for constructive critisism that will lead to improved and more robust research (Tinker, 2001). Scrutiny provided by others who are independent of the proposal, including people who have considerable research experience, can help anticipate difficulties. Amendments can save time and anxiety later on and provide reassurance and so make the time involved in submitting a proposal for ethical review a worthwhile investment.

An unfortunate and unintended consequence of the development of ethical codes and ethics committees is to have dulled the ethical awareness of researchers (Valentine, 2005; Dixon-Woods et al., 2007). The focus has shifted to meeting criteria rather than reflecting on a research proposal's specific issues. The letter of approval from an ethics committee does not end ethical responsibilities of a researcher. Ethics continue to be ever present throughout the course of the study. Furthermore, committees and codes have limitations.

Not only may unanticipated problems arise but decisions made by ethics committees have been demonstrated to be unethical even within their own criteria (Robinson and Carter, 2007). Many ethics committees and ethical codes are based on models designed for the conduct of medical research even where rooted in the social sciences. The code of conduct developed recently by the Economic and Social Research council is largely based on principles developed for medical research (Dyer and Demereritt, 2008). The choice of research question also has ethical dimensions which should be reflected on by researchers but are likely to fall outside of the remit of more medically focussed ethics committees. Many concerns are of course shared by medicine and the social sciences, but not all. Researchers, including hospital chaplains, have an ethical responsibility not only to meet stated requirements but to reflectively consider other and wider issues.

Medical ethics were originally designed to oversee studies such as drug trials which pose considerable risk to participants (Dyer and Demeritt, 2008). Not surprisingly, informed consent is an important pillar of such work. Applying such an ethical approach where methods other than Randomised Control Trials are being used can be problematic. For example, informed consent causes difficulties for researchers using ethnographic approaches, a point discussed by Oeye et al (2007) in relation to a study taking part in a psychiatric hospital in Norway. Ethnographic methods, specifically in this case participant observation, involve researchers observing the behaviour of others sometimes without the awareness of participants. Informing those taking part in the study can be problematic methodologically (they might alter their behaviour rendering the study pointless) or practically (getting in touch with everyone who enters the site of the study may be impossible). These methods, however, may be the most appropriate to the research question. Adopting a less effective approach might be on balance a better option, but alternatively may compromise the research.

The negotiations between the researchers in the Oeye et al. study with a medical ethics committee provide a useful case study of how developing the ethical basis of a study is a process rather than simply the meeting of objectives. The hospital management board and senior nurses in the hospital in which the study was to take place agreed to the proposal. The medical ethics committee, however, objected to the researchers not firstly getting consent in writing from all participating. The committee made two suggestions: either patients who did not wish to take part could be moved to another ward (the researchers thought would be itself unethical); or the researcher could be conducted in another unit in which everybody agreed to taking part (which the researchers thought was impractical). The researchers discussed their proposal with the committee prior to the study starting and during the early stages. They proceeded after writing to patients on the ward involved. Researchers made a point of not using observations in analysis or reporting of those from whom no consent was attained. Various limitations were created but nonetheless the study was able to proceed in such a way as to meet the ethics committee's initial objections and that still met the needs of researchers from point of view of addressing their research question.

The point of note as regards this paper is that the researchers did not just accept the initial proposals from the ethics committee but were prepared to discuss and negotiate. Furthermore, they did not just 
accept the committee's judgement with regard to the first suggestions. Their study required considerable discussion and negotiation to find an approach acceptable from point of view of research needs and research ethics stipulations. The approach they used is unlikely to be applicable to other studies and the effectiveness of their resulting methods will doubtless remain open to criticism. The point I want to draw out here is their active participation in the ethics process. They did not simply accept the initial reluctance of an ethics committee but instead discussed other ways forward.

Chaplains engaging in research should thus see themselves as a part of the process of developing the ethical dimensions of their research. I have already suggested that acceptance of a proposal as ethical does not end responsibilities. The converse also holds where an ethics committee deems a proposal to be not ethical without good reason. Careful consideration should of course be given to the reasons for rejection. If after doing so the chaplain believes the decision to be incorrect then he or she should feel empowered to challenge. Doing so would require some confidence and the ability to clearly and articulately argue the case. Chaplains, as I have already suggested, are well placed to do just this. They are firstly experienced in dealing with ethics in the course of their work and secondly bring perspectives to ethical deliberations that may otherwise be missing.

This point, that a faith based approach can bring dimensions that may otherwise be missing, is illustrated by Cloke (2002). Cloke, a geographer, has suggested that his Christian perspective provides him with a framework that brings a dimension to his ethical considerations that would otherwise be absent, specifically a concern for those who are disadvantaged. I would dispute that concerns for powerless groups require Christian belief but nonetheless accept that his faith has provided him with a basis on which ethical concerns come to the fore. Chaplains will have a set of beliefs that similarly provide understandings different from researchers coming from other traditions. As such, their input beyond acquiescence to current orthodoxies is to be valued.

An initial response to the ever growing volumes of ethical codes, time-consuming and difficult forms for the ethics committees, or indeed to consideration of ethical dilemmas is to decide not to proceed. However, research is important to developing a better understanding of other people's lives. Research has highlighted, amongst other findings, the impact of social inequalities. In the absence of research, such injustices would go unnoticed or be more easily dismissed. Similar arguments can be made for research on countless other subjects. Research is therefore important and not conducting it out of concern for potential harm is too simplistic and arguably unethical.

This final point, the suggestion that there is an ethical dimension to ensuring that research is done, is strengthened if a balanced view of risks is taken. Most social research involves participants experiencing risks no greater than those encountered in day-to-day life (Dyer and Demeritt, 2008). Medical research (for which ethical codes were originally devised) often involves administering drugs that have potentially lethal consequences. Social research that involves such risks is rare. This is not to belittle the ethical issues involved, but rather to urge that problems are kept in perspective.

Social research has and continues to make an important contribution to understanding the lives of others and the impact of interventions or policies. This point is made more apparent by reading the lists of papers presented in past issues of this journal with their concerns for others. Chaplains should see research as making important contributions to their work and a practice which is an integral part of their work, especially if their practice is to be ethical. Far from being a bureaucratic and forbidding process the ethical component of a study can be seen as enriching. Of course there are risks attached, few worthwhile endeavours are free from risk. Careful appraisal in consultation with ethics committees can minimise these and provide frameworks for addressing problems that do arise. Being an active part of this process ensures that the research is more robust, the chaplain is better placed to react where issues arise, and can contribute to the ongoing development of ethical understandings for the wider research community.

Chaplains conducting research have a central role in the ethical conduct of their research throughout the process, from proposal design to disseminating results, even in the strictures of ever increasing demands from ethics committees. Furthermore, 
engaging fully intellectually in ethical dimensions of research can enrich the experience for the chaplains, and contribute to a more ethically reflective research community.

\section{References}

BRITISH SOCIOLOGICAL ASSOCIATION 2002 Statement of ethical practice for the British Sociological Association, http://www.britsoc.co.uk/NR/rdonlyres/801B9A625CD3-4BC2-93E1FF470FF10256/0/StatementofEthicalPractice.pdf (last accessed 23 January 2010).

CLOKE P 2002 Deliver us from evil? Prospects for living ethically and acting politically in human geography Progress Human Geography 265 587-604 DIXON-WOODS M ANGELL E ASHCROFT RE \& BRYMAN A. 2007 Written work: the social functions of research ethics committee letters, Social Science and Medicine, 65 792-802.

DYER S \& DEMERITT D 2008 Unethical review? Why it is wrong to apply the medical model of research governance to human geography, Progress in Human Geography 331 146-64.

ESRC 2008 Research Ethics Framework, Economic and Social Research Council, Swindon, http://www.esrc.ac.uk/ESRCInfoCentre/Images/ES RC_Re_Ethics_Frame_tcm6-11291.pdf (last accessed 28 January 2010).
OEYE C BJELLAND A.K. \& SKORPEN A 2007

Doing participant observation in a psychiatric hospital - research ethics resumed, Social Science and Medicine, 65 2296-2306.

ROYAL COLLEGE OF NURSING 2009 Research ethics: RCN guidance for nurses, http://www.rcn.org.uk/ data/assets/pdf file/0010/7 8742/003138.pdf (last accessed 23 January, 2010). ROBINSON L MURDOCH-EATON D \& CARTER Y 2007 NHS ethics committees: still need more common sense and less bureaucracy, BMJ, 335: 6.

SOCIAL RESEARCH ASSOCIATION 2003 Ethical guidelines, http://www.thesra.org.uk/documents/pdfs/ethics03.pdf (last accessed 23 January 2010).

TINKER A 2001 Ethics committees - help or hindrance?, Journal of the British Society of Gerontology, 11 11-12.

VALENTINE G 2005 Geography and ethics: moral geographies? Ethical commitment in research and teaching, Progress in Human Geography 29 4: 483487.

Dr Iain Atherton is a lecturer in the Department of Nursing and Midwifery, University of Stirling, Highand Campus, Inverness. 